\title{
Smart Contracts and Automation of Private Relationships
}

\author{
Pietro Sirena and Francesco Paolo Patti
}

\subsection{INTRODUCTION}

Technological advancements and cyberspace have forced us to reconsider the existing limitations of private autonomy. Within the field of contract law, according to regulatory strategies, the public dimension affects private interests in several ways. These include the application of mandatory rules and enforcement mechanisms capable of obtaining certain results and granting a sufficient level of effectiveness. This is particularly the case in European contract law, where the law pursues regulatory goals related to the establishment and the enhancement of a common European market. ${ }^{1}$

The digital dimension represents a severe challenge for European and national private law. ${ }^{2}$ In order to address the implications of the new technologies on private law, recent studies were conducted inter alia on algorithmic decisions, digital platforms, the Internet of Things, artificial intelligence, data science, and blockchain technology. The broader picture seems to indicate that, in the light of the new technologies, the freedom to conduct business has often turned into power. Digital firms are no longer only market participants: rather, they are becoming market makers capable of exerting regulatory control over the terms on which others can sell goods and services. ${ }^{3}$ In so doing, they are replacing the exercise of states' territorial sovereignty with functional sovereignty. This situation

1 See generally Stefan Grundmann, 'The Structure of European Contract Law' (2001) 4 Eur Rev Contr L 505. On mandatory rules on consumer contracts, see Gerhard Wagner, 'Zwingendes Vertragsrecht' in Horst Eidenmüller et al., Revision des Verbraucher-acquis (Mohr Siebeck 2011) 1, 1-4.

$=$ See especially Stefan Grundmann and Philipp Hacker, "The Digital Dimension as a Challenge to European Contract Law' in Stefan Grundmann (ed.), European Contract Law in the Digital Age (Intersentia 2018) 3-45; Alberto De Franceschi and Reiner Schulze (eds.), 'Digital Revolution - New Challenges for the Law: Introduction' in Digital Revolution - New Challenges for the Law (C. H. Beck 2019) 1-15; Matthias Weller and Matthias Wendland (eds.), Digital Single Market - Bausteine eines eines Digitalen Binnenmarkts (Mohr Siebeck 2019).

3 Alessandro Morelli and Oreste Pollicino, 'Metaphors, Judicial Frames and Fundamental Rights in Cyberspace' (2020) Am J Comp L 1, 26 (forthcoming). 
raised concern in different areas of law and recently also in the field of competition law. ${ }^{4}$

As Lawrence Lessig pointed out, in the mid-199os, cyberspace became a new target for libertarian utopianism where freedom from the state would reign. ${ }^{5}$ According to this belief, the society of this space would be a fully self-ordering entity, cleansed of governors and free from political hacks. Lessig was not a believer of the described utopian view. He correctly pointed out the need to govern cyberspace, as he understood that left to itself, cyberspace would become a perfect tool of 'Control. Not necessarily control by government. ${ }^{6}$ These observations may be connected to the topic of private authorities who exercise power over other private entities with limited control by the state. The issue was tackled in a study by an Italian scholar which is now more than forty years old, ${ }^{7}$ and more recently by several contributions on different areas of private law. ${ }^{8}$ The emergence of private authorities was also affirmed in the context of global governance. ${ }^{9}$ These studies were able to categorize forms and consequences of private authorities, to identify imbalances of power, envisage power-related rules of law, and question the legitimacy of private power. One of the main problems is that private authorities can be resistant to the application and enforcement of mandatory rules.

The present chapter aims to investigate whether and how blockchain technology platforms and smart contracts could be considered a modern form of private authority, which at least partially escapes the application of mandatory rules and traditional enforcement mechanisms. ${ }^{10}$ Blockchain technology presents itself as democratic in nature, as it is based on an idea of radical decentralization. ${ }^{11}$ This is in stark contrast to giant Big Tech corporations working over the internet in the fields of social networking, online search, online shopping, and so forth; with blockchain,

4 Viktoria H. S. E. Robertson, 'Excessive Data Collection: Privacy Considerations and Abuse of Dominance in the Era of Big Data' (2020) 57 CML Rev 161-190. On price discrimination based on big data, see Chiara Muraca and Mariateresa Maggiolino, 'Personalized Prices under EU Antitrust rules' (2019) Eu Comp L Rev 483.

5 Lawrence Lessig, Code. Version 2.0 (Basic Books 2006) 2: 'The space seemed to promise a kind of society that real space would never allow-freedom without anarchy, control without government, consensus without power.'

6 Lessig (n 5) 3. On whether cyberspace required new regulations, see also Frank H. Easterbrook, 'Cyberspace and the Law of the Horse' (1996) U Chicago Leg Forum 207-216.

7 C. Massimo Bianca, Le autorità private (Jovene 1977).

8 See Florian Möslein (ed.), Private Macht (Mohr Siebeck 2016); Kit Barker et al. (eds.), Private Law and Power (Hart Publishing 2017); Pietro Sirena and Andrea Zoppini (eds.), I poteri privati e il diritto della regolazione (Roma Tre Press 2018).

9 Rodney Bruce Hall and Thomas J Biersteker, The Emergence of Private Authority in Global Governance (Cambridge University Press 2009).

10 A relevant problem that is not tackled in the present essay is the liability of the blockchain-platforms' operators in cases of bugs or hacks. See Luigi Buonanno, 'Civil Liability in the Era of New Technology: The Influence of Blockchain' (16 September 2019). Bocconi Legal Studies Research Paper No. 3454532, September 2019, Available at SSRN: https://ssrn.com/abstract=3454532 (outlining a 'European strategy' to face the severe challenges).

"See William Magnuson, Blockchain Democracy. Technology, Law and the Rule of the Crowd (Cambridge University Press 2020) 61-9o. 
technology users put their trust in a network of peers. Nevertheless, as happened with the internet, market powers could create monopolies or highly imbalanced legal relationships. ${ }^{12}$ In this sense, contractual automation seems to play a key role in understanding the potentialities and the risks involved in the technology. In general terms, one of the main characteristics of a smart contract is its self-executing character, which should eliminate the possibility of a breach of contract. But smart contracts may also provide for effective self-help against breaches of traditional contracts. Finally, when implemented on blockchain platforms, smart contract relationships may also benefit from the application of innovative dispute resolution systems, which present themselves as entirely independent from state authorities.

\subsection{SMART CONTRACTS: MAIN CHARACTERISTICS}

In his well-recognized paper entitled 'Formalizing and Securing Relationships on Public Networks', Nick Szabo described how cryptography could make it possible to write computer software able to resemble contractual clauses and bind parties in a way that would almost eliminate the possibility of breaching an agreement. ${ }^{13}$ Szabo's paper was just a first step, and nowadays basically every scholar interested in contract law may expound on the essentials of how a smart contract functions. Some jurisdictions, such as in Italy, have also enacted rules defining a smart contract. ${ }^{14}$ The great interest is due to the growing adoption of Bitcoin and other blockchain-based systems, as for instance Ethereum. ${ }^{15}$ The latter provides the necessary technology to carry out Szabo's ideas.

Smart contracts do not differ too greatly from natural language agreements with respect to the parties' aims or interests. ${ }^{16}$ In reality, except where the decision to conclude the contract is taken by an 'artificial intelligent agent', they solely form a technological infrastructure that makes transactions cheaper and safer. ${ }^{17}$ The main

12 Ibid. 5 .

13 Nick Szabo, 'Formalizing and Securing Relationships on Public Networks' (1997) 2 (9) First Monday, at https://doi.org/10.5210/fm.v2i9.548.

14 See article 8-ter Decreto legge 14 December 2018, n. 135 (converted in Legge 11 February 2019, n. 12): ‘Si definisce "smart contract" un programma per elaboratore che opera su tecnologie basate su registri distribuiti e la cui esecuzione vincola automaticamente due o più parti sulla base di effetti predefiniti dalle stesse.' ('Smart contracts' are defined as computer programs that operate on distributed registers-based technologies and whose execution automatically binds two or more parties according to the effects predefined by said parties.) With respect to the Italian provision, see Andrea Stazi, Automazione contrattuale e contratti intelligenti. Gli smart contracts nel diritto comparato (Giappichelli 2019) 134-135.

15 See Primavera De Filippi and Aaron Wright, Blockchain and the Law. The Rule of Code (Harvard University Press 2018) 74 .

16 See generally Eliza Mik, 'The Resilience of Contract Law in Light of Technological Change' in Michael Furmston (ed.), The Future of the Law of Contract (Routledge 2020) 112 (opposing all theories seeking to modify the principles of contract law due to the fact that a given transaction is mediated by technology).

17 See Kevin Werbach and Nicholas Cornell, 'Contracts Ex Machina' (2017) 67 Duke LJ 313, 318 (declaring that 'Algorithmic enforcement allows contracts to be executed as quickly and cheaply as other computer code. Cost savings occur at every stage, from negotiation to enforcement, especially in replacing judicial enforcement with automated mechanisms'). 
quality of a smart contract relies on the automation of contractual relationships, as the performance is triggered by an algorithm in turn triggered by the fulfilment of certain events. In this sense, there is often talk of a distinction between the notions of 'smart contract' and 'smart legal contract' with the result that contractual automation in the majority of cases affects only its performance. ${ }^{18}$ In contrast, the contract as such (i.e., the legal contract) is still a product of the meetings of the minds, through an offer and an acceptance. ${ }^{19}$ In many cases, this induces parties to 'wrap' the smart contract in paper and to 'nest' it in a certain legal system. ${ }^{20}$

It is therefore often argued that 'smart contract' is a misnomer as the 'smart' part of the contract in reality affects only the performance. ${ }^{21}$ In addition, smart contracts are not intelligent but rely on an 'If-Then' principle, which means, for instance, that a given performance will be executed only when the agreed-upon amount of money is sent to the system. ${ }^{22}$ These critics seem to be correct, and this goes some way to demystifying the phenomenon, ${ }^{23}$ which is sometimes described as a game-changer that will impact every contractual relationship. ${ }^{24}$ Discussions are beginning to be held on automated legal drafting, through which contractual clauses are shaped on the basis of big data by machine learning tools and predictive technologies, but for now, they do not really affect the emerging technology of smart contracts on blockchain platforms. ${ }^{25}$ The latter work is based on rather simple software protocols

See Mateja Durovic and Fanciszek Lech, 'The Enforceability of Smart Contracts' (2019) 5 Italian LJ $493,499$.

19 See especially Gregorio Gitti, 'Robotic Transactional Decisions' (2018) Oss dir civ comm 619, 622; Mateja Durovic and André Janssen, "The Formation of Blockchain-Based Smart Contracts in the Light of Contract Law' (2018) 26 Eur Rev Priv L 753-771 ("neither on-chain nor off-chain smart contracts are really challenging the classic elements of English Common Law on formation of contracts - offer and acceptance, consideration, intention to create legal relations, and capacity').

20 Jason G. Allen, "Wrapped and Stacked: "Smart Contracts" and the Interaction of Natural and Formal Language' (2018) 14 Eur Rev Contr L 307-343.

${ }^{21}$ See Scott A. McKinney, Rachel Landy, and Rachel Wilka, 'Smart Contracts, Blockchain, and the Next Frontier of Transactional Law' (2018) 13 Wash J L Tech \& Arts 313, 322 ("A smart contract, however, is not actually very "smart." Smart contracts do not (at least, as of the date of this Article) include artificial intelligence, in that a smart contract does not learn from its actions'); Jeffrey M. Lipshaw, 'The Persistence of Dumb Contracts' (2019) 2 Stan J Blockchain L \& Pol'y 1. With specific regard to the well-known 'TheDAO' hack, see the critics of Adam J. Kolber, 'Not-So-Smart Blockchain Contracts and Artificial Responsibility' (2018) 21 Stan Tech L Rev 198. See also Blaise Carron and Valentin Botteron, 'How Smart Can a Contract Be?' in Daniel Kraus et al. (eds.), Blockchains, Smart Contracts, Decentralised Autonomous Organisations and the Law (Edward Elgar 2019) 101.

22 See, e.g., Eliza Mik, 'Smart Contracts: Terminology, Technical Limitations and Real World Complexity' (2017) 9 L Innovation \& Tech 269.

23 See, in this regard, André Janssen, 'Demystifying Smart Contracts' in Corjo J. H. Jansen et al. (eds.), Onderneming en Digitalisering (Wolters Kluwer 2019) 15-29, at 22-23.

24 See, e.g., the optimistic view of Jeff Lingwall and Ramya Mogallapu, 'Should Code Be Law: Smart Contracts, Blockchain, and Boilerplate' (2019) 88 UMKC L Rev 285.

25 See, generally, Kathryn D. Betts and Kyle R. Jaep, "The Dawn of Fully Automated Contract Drafting: Machine Learning Breathes New Life into a Decades Old Promise' (2017) 15 Duke L \& Tech Rev 216; Lauren Henry Scholz, 'Algorithmic Contracts' (2017) 20 Stan Tech L Rev 128; Spencer Williams, 
and other code-based systems, which are programmed ex ante without the intervention of artificial intelligence. ${ }^{26}$

Nevertheless, the importance of the 'self-executing' and 'self-enforcing' character of smart contracts should not be undermined. Most of the benefits arising from the new technology are in fact based on these two elements, which represent a source of innovation for general contract law. The 'self-executing' character should eliminate the occurrence of contractual breaches, whereas the 'self-enforcing' character makes it unnecessary to turn to the courts in order to obtain legal protection. ${ }^{27}$ In addition, the code does not theoretically require interpretation, as it should not entail the need to explain ambiguous terms. ${ }^{28}$ Currently, it is not clear whether smart contracts will diminish transaction costs, due to the complexity of digital solutions and the need to acquire the necessary knowledge. ${ }^{29}$ For reasons that will be outlined, costs of implementation seem not to harm the potential spread of smart contracts, especially in the fields of consumer contracts and the Internet of Things.

\subsection{SELF-EXECUTION AND SELF-ENFORCEMENT}

As stated before, through the new technology one or more aspects of the contract's execution become automated, and having once entered into the contract, parties cannot prevent performance from being executed. Smart contracts use blockchain to ensure the transparency of the contractual relationship and to create trust in the capacity to execute the contract, which depends on the involved technology. As previously stated, the operation is based on 'If-Then' statements, which are one of the most basic building blocks of any computer program.

Undeniably, such a technology can easily govern the simple contractual relationship, in which the system has only to determine where a given amount of money has been paid in order to have something in return (e.g., a digital asset) or where the

'Predictive Contracting' (2019) Colum Bus L Rev 621. With respect to the differences between traditional contracts concluded through particular technological devices and contractual automation, which involves the use of AI, see Tom Allen and Robin Widdison, 'Can Computers Make Contracts' (1996) 9 Harv J L \& Tech 25. On the philosophical implications, cf. Karen Yeung, "Why Worry about Decision-Making by Machine?' in Karen Yeung and Martin Lodge (eds.), Algorithmic Regulation (Oxford University Press 2019) 21.

26 On the different technological steps that lead to a smart contract execution on a blockchain platform, see Michèle Finck, 'Grundlagen und Technologie von Smart Contracts' in Martin Fries and Boris P. Paal (eds.), Smart Contracts (Mohr Siebeck 2019) 1, 4-8. See also Valentina Gatteschi, Fabrizio Lamberti, and Claudio et al., 'Technology of Smart Contracts' in Larry A. DiMatteo et al. (eds.), The Cambridge Handbook of Smart Contracts, Blockchain Technology and Digital Platforms (Cambridge University Press 2019) 37.

27 See Finck (n 26) 9.

28 Cf. Michel Cannarsa, 'Interpretation of Contracts and Smart Contracts: Smart Interpretation or Interpretation of Smart Contracts?' (2018) 26 Eur Rev Priv L 773 (pointing out that computer language is deterministic (just one meaning and one result are conceivable), whereas natural language is open to more and potential different meanings).

29 Janssen (n 23) at 24-25. 
performance is due when certain external conditions of the real world are met. Since a modification of the contractual terms of a smart contract implemented on a blockchain platform is hardly possible, execution appears certain and personal trust or confidence in the counterparty is not needed. $3^{\circ}$ This has led to the claim that in certain situations, contracting parties will face the 'cost of inflexibility', as blockchain-based smart contracts are difficult to manipulate and therefore resistant to changes. ${ }^{31}$ In fact, smart contracts are built on the assumption that there will not be modifications after the conclusion of the contract. As a result, if or when circumstances relevant to the smart contract change, a whole new contract would need to be written.

'Inflexibility' is often considered a weakness of smart contracts. ${ }^{32}$ Supervening events and the change of circumstances may require parties to intervene in the contractual regulation and provide for some amendments. ${ }^{33}$ Therefore, legal systems contain rules that may lead to a judicial adaptation of the contract, sometimes through a duty to renegotiate its content. ${ }^{34}$ In this regard, smart contracts differ from traditional contracts, as they take an ex ante view instead of the common ex post judicial assessment view of law. ${ }^{35}$

In reality, this inflexibility does not constitute a weakness of smart contracts. Instead, it makes clear that self-execution and self-enforcement could bring substantial benefits only in certain legal relationships, where parties are interested in a simple and instantaneous exchange. Moreover, self-execution does not necessarily affect the entire agreement. Indemnity payouts, insurance triggers, and various other provisions of the contract could be automated and self-fulfilling, while other provisions may remain subject to an ordinary bargain and be expressed in natural language. ${ }^{36}$ One can therefore correctly state that smart contracts automatically perform obligations which arise from legal contracts but not necessarily all the obligations. Finally, it should be observed that future contingencies that impact the contractual balance, as for instance an increase of the raw materials' price, could be assessed through lines of code, in order to rationally adapt the contractual performance. ${ }^{37}$

Rolf H. Weber, 'Smart Contracts: Do We Need New Legal Rules?' in De Franceschi and Schulze (n 2) 299, 302.

31 Enrico Seidel, Andreas Horsch, and Anja Eickstädt, 'Potentials and Limitations of Smart Contracts: A Primer from an Economic Point of View' (2020) 31 Eur Bus L Rev 169, 176-179.

32 Jeremy M. Sklaroff, 'Smart Contracts and the Cost of Inflexibility' (2017) 166 U Penn L Rev 263 (arguing that forms of flexibility - linguistic ambiguity and enforcement discretion - create important efficiencies in the contracting process). See also Finck (n 26) 11.

33 See generally Rodrigo A. Momberg Uribe, The Effect of a Change of Circumstances on the Binding Force of Contracts Comparative Perspectives (Intersentia 2011).

34 Ibid.

35 Eric Tjong Tjin Tai, 'Force Majeure and Excuses in Smart Contracts' (2018) 26 Eur Rev Priv L 787.

${ }^{6}$ See McKinney, Landy, and Wilka (n 21) 325.

37 Ibid. at 338. 
The latter issue makes clear that often the conditions for contractual performance relate to the real and non-digital world outside of blockchains. It is therefore necessary to create a link between the real world and the blockchain. Such a link is provided by the so-called oracles, which could be defined as interfaces through which information from the real world enters the 'digital world'. There are different types of oracles, ${ }^{38}$ and some scholars argue that their operation harms the selfexecuting character of smart contracts, because the execution is eventually remitted to an external source. ${ }^{39}$ Due to the technology involved, oracles do not seem to impact the automated execution of smart contracts. The main challenge with oracles is that contracting parties need to trust these outside sources of information, whether they come from a website or a sensor. As oracles are usually third-party services, they are not subject to the security blockchain consensus mechanisms. Moreover, mistakes or inaccuracies are not subject to rules that govern breach of contract between the two contracting parties.

In the light of the above, self-execution and self-enforcement assure an automated performance of the contract. Nevertheless, whether due to an incorrect intervention of an oracle, for a technological dysfunction, or for an error in the programming, things may go wrong and leave contracting parties not satisfied. In these cases, there could be an interest in unwinding the smart contract. According to a recent study, ${ }^{4}$ this can be done in three ways. Needless to say, the parties can unwind the legal contract in the old-fashioned way by refunding what they have received from the other party, be it voluntarily or with judicial coercion. At any rate, it would be closer to the spirit of fully automated contracts, if the termination of the contract and its unwinding could also be recorded in the computer code itself and thus carried out automatically. ${ }^{41}$ Finally, it is theoretically possible to provide for technical modifications of the smart contract in the blockchain. The three options, as also argued by the author, ${ }^{42}$ are not easily feasible and there is the risk of losing the advantages related to self-execution. It is therefore of paramount importance to devote attention

$3^{8}$ See, e.g., 'software oracles', which handle information data that originates from online sources, as temperature, prices of commodities and goods, flight or train delays, and so forth; 'hardware oracles', which take information directly from the physical world; 'inbound oracles', which provide data from the external world; 'outbound oracles', which have the ability to send data to the outside world; and 'consensus-based oracles', which get their data from human consensus and prediction markets (e.g., Augur, based on Ethereum).

39 See Janssen (n 23) 23 (declaring that every oracle added to a smart contract decreases the selfenforcement level).

$4^{\circ}$ Olaf Meyer, 'Stopping the Unstoppable: Termination and Unwinding of Smart Contracts' (2020) EuCML 17, at 20-24.

${ }^{41}$ See Larry A. DiMatteo and Cristina Poncibó, 'Quandary of Smart Contracts and Remedies: The Role of Contract Law and Self-Help Remedies' (2018) 26 Eur Rev Priv L 805 (observing: 'It is in the area of self-enforcement and remedies where the vision of smart contracts confronts the reality of contract law and business lawyering. Smart contracts need to be drafted by lawyers, focused on client interests and not technological prowess').

$4^{2} \quad$ Meyer (n 40) 24 . 
to the self-help and dispute resolution mechanisms developed on blockchainplatforms. ${ }^{43}$

\subsection{AUTOMATED SELF-HELP}

The functioning of smart contracts may also determine a new vast array of self-help tools (i.e., enforcement mechanisms that do not require the intervention of state power). The examples of self-help that have recently been discussed are related to Internet of Things technology. ${ }^{44}$ The cases under discussion affect self-enforcement devices that automatically react in the presence of a contractual breach and put the creditor in a position of advantage with respect to that of the debtor. The latter, who is in breach, cannot exercise any legal defence vis-à-vis automated self-help based on algorithms. Scholars who addressed the issue stressed the dangers connected to a pure exercise of private power through technology. ${ }^{45}$

Among the most frequent examples, there is the lease contract, for which a smart contract could automatically send a withdrawal communication in case of a twomonth delay in the payment of the lease instalment. If the lessee does not pay the due instalment within one month, the algorithm automatically locks the door and prevents the lessee from entering into the apartment. Another example is the 'starter interrupt device', which can be connected to a banking loan used to buy a vehicle. If the owner does not pay the instalments, the smart contract prevents the vehicle from starting. Similar examples are present in the field of utilities (gas, electricity, etc.). ${ }^{6}$ If the customer does not pay for the service, the utilities are no longer available. In looking to general contractual remedies, the potentiality of such self-help instruments appears in reality almost unlimited. Automation could also affect the payment of damages or liquidated damages.

Self-help devices take advantage of technology and put in the creditors' hands an effective tool, which - at the same time - reduces the costs of enforcement and significantly enhances the effectiveness of contractual agreements. This is mainly due to the fact that recourse to a court is no longer necessary. Contractual

44 Robin Matzke, 'Smart Contracts statt Zwangsvollstreckung? Zu den Chancen und Risiken der digitalisierten privaten Rechtsdurchsetzung' in Fries and Paal (n 26) 99, 103. See generally, on Internet of Things liability issues, Christiane Wendehorst, 'Consumer Contracts and the Internet of Things' in Reiner Schulze and Dirk Staudenmayer (eds.), Digital Revolution: Challenges for Contract Law in Practice (Hart Publishing 2016) 189; Francesco Mezzanotte, 'Risk Allocation and Liability Regimes in the IoT' in De Franceschi and Schulze (n 2) 169; specifically on consumer contracts, Katarzyna Kryla-Cudna, 'Consumer Contracts and the Internet of Things' in Vanessa Mak et al. (eds.), Research Handbook in Data Science and Law (Edward Elgar 2018) 83.

45 See Thomas Riehm, 'Smart Contracts und verbotene Eigenmacht' in Fries and Paal (n 26) 85; Florian Möslein, 'Legal Boundaries of Blockchain Technologies: Smart Contracts as Self-Help?' in De Franceschi and Schulze (n 2) 313.

$4^{6}$ With reference to the German legal system, see Christoph G. Paulus and Robin Matzke, 'Smart Contracts und Smart Meter - Versorgungssperre per Fernzugriff (2018) NJW 1905. 
automation may increase the awareness of the importance of fulfilling obligations in time. Moreover, the reduction of costs related to enforcement may lead to a decrease in prices for diligent contracting parties. At any rate, as correctly pointed out, the described 'technological enforcement' - although effective - does not necessarily respect the requirements set by the law. ${ }^{47}$ In other words, even if smart contracts are technologically enforceable, they are not necessarily also legally enforceable. ${ }^{48}$ In the examples outlined previously, it is possible to imagine a withdrawal from the contract without due notice or the payment of an exorbitant sum of money as damages.

How should the law react to possible deviations between the code and the law? It seems that a kind of principle of equivalent treatment should provide guidance to resolving cases: ${ }^{49}$ limits that exist for the enforcement of traditional contracts should be extended to smart contracts. From a methodological point of view, practical difficulties in applying the law should not prevent an assessment of the (un)lawful character of certain self-help mechanisms. In cases where the law provides for mandatory proceedings or legal steps in order to enforce a right, the same should in principle apply to smart contracts.

Nevertheless, evaluation of the self-help mechanisms' lawfulness should not be too strict, and should essentially be aimed at protecting fundamental rights - for instance, the right to housing. The 'automated enforcement' relies on party autonomy and cannot be considered as an act of oppression exercised by a 'private power' per se. Therefore, apart from the protected rights, the assessment should also involve the characteristics of the contracting parties and the subject matter of the contract. In this regard, it was correctly pointed out that EU law provides for some boundaries of private autonomy in consumer contracts, which apply to smart contracts. ${ }^{50}$

For instance, the unfair terms directive ${ }^{51}$ indicates that clauses, which exclude or hinder a consumer's right to take legal action, may create a significant imbalance in parties' rights and obligations. ${ }^{52}$ The same is stated with respect to clauses irrevocably binding the consumer to terms with which she or he had no real opportunity of becoming acquainted before the conclusion of the contract. ${ }^{53}$ According to

47 Möslein (n 45) 318.

$4^{8}$ See Max Raskin, 'The Law and Legality of Smart Contracts' (2017) 1 Geo L Tech Rev 305 (pointing out: "The central problem in the final question of contract law is what happens when the outcomes of the smart contract diverge from the outcomes that the law demands'). With respect to blockchain technology, see also Roger Brownsword, 'Automated Transactions and the Law of Contract. When Codes Are Not Congruent' in Furmston (n 16) 94, 102 (declaring: 'If such technological enablement or disablement is at variance with what a court applying the law of contract would order, then we have a question of non-congruence').

49 Such a principle is discussed, in the context of contractual automation, by Brownsword, ibid. 102-110.

5० See Möslein (n 45) 323-324.

${ }^{51}$ Council Directive 93/13/EEC of 5 April 1993 on unfair terms in consumer contracts [1993] OJ L 95/29.

52 Ibid., annex, terms referred to in article $3(3)$, let (q).

53 Ibid., let (i). 
prevailing opinion, the scope of application of the unfair terms directive also covers smart contracts, even if the clauses are expressed through lines of code. ${ }^{54}$

Undeniably, smart contracts may pose difficulties to consumers when it comes to exercising a right against illicit behaviour on behalf of the business. At any rate, it would not be proper to consider the self-help systems directly unlawful. The enforcement of EU consumer law is also granted by public authorities, ${ }^{55}$ which in the future may exercise control with respect to the adopted contractual automation processes and require modifications in the computer protocol of the businesses. If the self-help reacts to a breach of the consumer, it should not in principle be considered unfair. On the one hand, contractual automation may provide for lower charges, due to the savings in enforcement costs. On the other hand, it could augment the reliability of consumers by excluding opportunistic choices and making them immediately aware of the consequences of the breach. Finally as will be seen - technological innovation must not be seen only as a menace for consumers, as it could also provide for an improvement in the application of consumer law and, therefore, an enhancement of its level of effectiveness. ${ }^{56}$

\subsection{AUTOMATED APPLICATION OF MANDATORY RULES}

A huge debate has affected the application of mandatory rules in the field of smart contracts. The risk that this innovative technology could be used as an instrument to fulfil unlawful activities, as the conclusion of immoral or criminal contracts, is often pointed out. ${ }^{57}$ The mode of operation may render smart contracts and blockchain technology attractive to ill-intentioned people interested in engaging in illicit acts.

Among the mandatory rules that may be infringed by smart contracts, special attention is dedicated to consumer law..$^{58}$ The characteristics of smart contracts make them particularly compatible with the interests of individual businesses in business-to-consumer relationships, as blockchain technology can guarantee a high level of standardization and potentially be a vehicle for the conclusion of mass contracts. In terms of the application of mandatory consumer law to smart contracts, opinions differ significantly. According to one author, smart contracts will determine the end of consumer law, as they may systematically permit businesses to

54 See Janssen (n 23) 26 (arguing that the unfair terms directive does not per se require a textual form of the contractual terms in order to apply).

55 On the different enforcement mechanisms in the field of unfair terms, see generally Hans-Wolfgang Micklitz, 'Unfair Terms in Consumer Contracts' in Norbert Reich et al. (eds.), European Consumer Law (2nd ed., Intersentia 2014) 136; Peter Rott, 'Unfair Contract Terms' in Christian Twigg-Flesner (ed.), Research Handbook on EU Consumer and Contract Law (Edward Elgar 2016) 287, 293-296.

56 On the notion of effectiveness in EU consumer law, see generally Norbert Reich, "The Principle of Effectiveness and EU Contract Law' in Jacobien Rutgers and Pietro Sirena (eds.), Rules and Principles in European Contract Law (Intersentia 2015) 45-68.

57 See generally De Filippi and Wright (n 15) at 86-88; Magnuson (n 11) 91-170.

$5^{8}$ See Tatiana Cutts, 'Smart Contracts and Consumers (2019) 122 W Va L Rev 389. 
escape its application. ${ }^{59}$ The claim has also been made that automated enforcement in the sector of consumer contracts amounts to an illusion, as mandatory rules prevent the use of automated enforcement mechanisms. ${ }^{60}$

Both opinions seem slightly overstated and do not capture the most interesting aspect related to smart consumer contracts. In fact, as has been recently discussed, technology and contractual automation may also be used as a tool to enforce consumer law and augment its level of effectiveness. ${ }^{61}$ Many consumers are indeed not aware of their rights or, even if they are, find it difficult to enforce them, due to emerging costs and a lack of experience. In addition, most consumer contractual claims are of insignificant value.

In this regard, a very good example is given by the EU Regulation on Compensation of Long Delay of Flights. ${ }^{62}$ The consumer has a right to get a fixed compensation, depending on the flight length, ranging from 125,00 to 600,00 euros. For the reasons outlined previously, what often happens is that consumers do not claim compensation; the compensation scheme thus lacks effectiveness. In the interest of consumers, reimbursement through a smart contract device has been proposed to automate the process. ${ }^{6} 3$ The latter would work on the basis of a reliable system of external interfaces. ${ }^{6}$ The proposal seems feasible and is gaining attention, especially in Germany, where the introduction of the smart compensation scheme in cases of cancellations or delays of flights has been discussed in Parliament. ${ }^{6}$

Two possible drawbacks are related to the described types of legislative intervention. Due to the wide distribution of the technology, which crosses national borders, the adoption of smart enforcement may produce strong distortions to international competition. ${ }^{66}$ For instance, the imposition of a smart compensation model as the

59 Alexander Savelyev, 'Contract Law 2.0: "Smart" Contracts as the Beginning of the End of Classic Contract Law', Higher School of Economics Research Paper No. WP BRP 71/LAW/2016, available at SSRN: https://ssrn.com/abstract $=2885241$.

6o See Danielle D'Onfro, 'Smart Contracts and the Illusion of Automated Enforcement' (2020) 61 Wash U J L \& Pol'y 173 (arguing that 'The volume of consumer protection laws, and their tendency to change over time, all but eliminates the prospect of coding smart contracts for perfect compliance exante').

61 See Oscar Borgogno, 'Smart Contracts as the (New) Power of the Powerless? The Stakes for Consumers' (2018) 26 Eur Rev Priv L 885; Janssen (n 23) 26-29.

62 Regulation (EC) No 261/2004 of the European Parliament and of the Council of 11 February 2004 establishing common rules on compensation and assistance to passengers in the event of denied boarding and of cancellation or long delay of flights, and repealing Regulation (EEC) No 295/91 [2004] OJ L 46/1. On the latter, see generally Ricardo Pazos, "The Right to a Compensation In Case Of Long Delay of Flights: A Proposal for a Future Reform' (2019) 27 Eur Rev Priv L 695(indicating i.a. the most relevant decisions of the European Court of Justice, which not seldom escape from the wording of the Regulation, especially with respect to long delays).

$6_{3}$ Borgogno (n 61) 897-898.

64 Ibid.

65 See for details Martin Fries, 'Schadensersatz ex machina' (2019) NJW 9o1; Anusch Alexander Tavakoli, 'Automatische Fluggast-Entschädigung durch smart contracts' (2020) ZRP 46.

66 See generally, on the regulatory challenges, Vincent Mignon, 'Blockchains - Perspectives and Challenges' in Kraus et al. (n 21) 1, 9. 
one discussed in Germany for the delay or the cancellation of flights may lead to an increase in the costs for flight companies that operate predominantly in that country. In order not to harm the aims of the internal market, smart enforcement should thus be implemented on a European level.

Another danger of the proposed use of smart contract devices is 'overenforcement'. ${ }^{67}$ The latter may be detrimental because it could prevent businesses from running an activity in order to escape liability and sanctions. The described adoption of technology in cases of flight delays may determine a digitalization of enforcement that drastically drops the rate of unpaid compensations to almost zero. The outlined scenario is not necessarily convenient for consumers, as the additional costs sustained by flight companies would probably be passed on to all customers through an increase in prices. The level of technology required to automatically detect every single delay of an airplane, and grant compensation to the travellers would probably lead to an explosion in costs for companies. While this may increase efficiency in the sector, it is questionable whether such a burden would be bearable for the flight companies. That is not to say that this risk automatically means strict enforcement is inherently evil: enforcement of existing rules is of course a positive aspect. Nevertheless, the economic problems it may give rise to should lead to the consideration of enforcement through technological devices as an independent element that could in principle also require modifications of substantive law. ${ }^{68}$ For instance, the technology could enable recognition of 'tailored' amounts of compensation depending on the seriousness of the delay. ${ }^{69}$

Many aspects seem uncertain, and it is not surprising that as things stand, smart enforcement mechanisms are not (yet) the core of legislative intervention. ${ }^{70}$ In reality, the current regulatory approach appears quite the opposite. Legislators are not familiar with the new technologies and are tending towards lightening the obstacles set by mandatory rules to blockchain technology with the aim of not harming its evolution. ${ }^{71}$ In many legal systems, contained 'regulatory sandboxes'

${ }_{7}$ See generally Franz Hofmann, 'Smart Contracts und Overenforcement - Analytische Überlegungen zum Verhältnis von Rechtszuweisung und Rechtsdurchsetzung' in Fries and Paal (n 26) 125.

68 Ibid., at 130.

69 In the aforementioned context of compensation for flight delays or cancellation, the somewhat futuristic proposals for a 'personalization' of the legal treatment could be of interest: see, generally, Ariel Porat and Lior Jacob Strahilevitz, 'Personalizing Default Rules and Disclosure with Big Data' (2014) 112 Mich L Rev 1417; Omri Ben-Shahar and Ariel Porat, 'Personalizing Mandatory Rules in Contract Law' (2019) 86 U Chi L Rev 255. With respect to consumer law, see also Christopher G. Bradley, 'The Consumer Protection Ecosystem: Law, Norms, and Technology' (2019) 97 Denv L Rev 35 .

70 See for an assessment Nico Kuhlmann, 'Smart Enforcement bei Smart Contracts' in Fries and Paal (n 26) 117.

${ }^{71}$ Michèle Finck, 'Blockchains: Regulating the Unknown' (2018) 19 German LJ 665, 687 (arguing that there are very few blockchain experts, and most regulators have not yet familiarized themselves with the available knowledge on the matter). On the different regulatory techniques concerning blockchain technology, see also Karen Yeung, 'Regulation by Blockchain: The Emerging Battle for 
were created, ${ }^{72}$ in order to support companies exercising their activities in the fields of fintech and blockchain technology. In general terms, regulatory sandboxes enable companies to test their products with real customers in an environment that is not subject to the full application of legal rules. In this context, regulators typically provide guidance, with the aim of creating a collaborative relationship between the regulator and regulated companies. The regulatory sandbox can also be considered a form of principles-based regulation because it lifts some of the more specific regulatory burdens from sandbox participants by affording flexibility in satisfying the regulatory goals of the sandbox. ${ }^{73}$ The described line of reasoning shows the willingness of legislators not to prevent technological progress and to help out domestic companies. The approach inevitably brings clashes when it comes to the protection of consumers' interests. ${ }^{74}$

\subsection{SMART CONTRACTS AND DISPUTE RESOLUTION}

Even if the claim 'code is law' or the expression 'lex cryptographica'75 may appear exaggerated, it seems evident that developers of smart contracts and blockchain platforms are aiming to create an order without law and implement a private regulatory framework. Achieving such a goal requires shaping a model of dispute resolution capable of resolving conflicts in an efficient manner, without the intervention of national courts and state power. ${ }^{76}$ The self-executing character of smart contracts may not prevent disputes occasionally arising between parties, connected for instance to defects in the product purchased or to the existence of an unlawful act. Moreover, the parties' agreement cannot always be encoded in 'if-then' statements and should be encompassed in non-deterministic notions and general clauses such as, for example, good faith and reasonableness. Unless artificial intelligence develops to the stage where a machine can substitute human reasoning in filling gaps of the contract or putting into effect general clauses, ${ }^{77}$ contractual disputes may still arise. The way smart contracts operate could lead parties to abandon the digital

Supremacy between the Code of Law and Code as Law' (2019) 82 Modern L Rev 207; Roger Brownsword, 'Smart Contracts: Coding the Transaction, Decoding the Legal Debates' in Philipp Hacker et al. (eds.), Regulating Blockchain. Techno-Social and Legal Challenges (Oxford University Press 2019).

72 Hilary J. Allen, 'Regulatory Sandboxes' (2019) 87 Geo Wash L Rev 579, 592 (declaring that the United Kingdom adopted a regulatory sandbox for fintech in 2016, and Australia, Bahrain, Brunei, Canada, Hong Kong, Indonesia, Malaysia, Mauritius, the Netherlands, Singapore, Switzerland, Thailand, and the United Arab Emirates have followed suit in adopting some form of regulatory sandbox model). See also Dirk A. Zetzsche, Ross P. Buckley, Janos N. Barberis, and Douglas W. Arner, 'Regulating a Revolution: From Regulatory Sandboxes to Smart Regulation' (2017) 23 Fordham J Corp \& Fin L 31 .

73 Allen, ibid.

74 See Magnuson (n 11) 183-184.

75 The notion 'lex cryptographica' is adopted by De Filippi and Wright (n 15) 5 .

${ }^{6}$ See generally Pietro Ortolani, "The Impact of Blockchain Technologies and Smart Contracts on Dispute Resolution: Arbitration and Court Litigation at the Crossroads' (2019) 24 Unif L Rev 430.

77 See Section 16.2. 
world and resolve their disputes off-chain. The issue is of high importance, as the practical difficulties of solving possible disputes between the parties could obscure the advantages connected to contractual automation. ${ }^{7^{8}}$

On this, one of the starting points in the discussions about dispute resolution in the field of blockchain is the observation that nowadays regular courts are not well enough equipped to face the challenges arising from the execution of lines of code. ${ }^{79}$ This claim could perhaps be correct at this stage, but it does not rule out courts acquiring the capacity to tackle such disputes in the future. In reality, a part of the industry is attempting to realize a well-organized and completely independent jurisdiction in the digital world through the intervention of particular types of oracles, which are usually called 'adjudicators' or 'jurors'.

Whether such a dispute resolution model can work strictly depends on the coding of the smart contract. As seen before, ${ }^{81}$ once a smart contract is running, in principle neither party can stop the protocol, reverse an already executed transaction, or otherwise amend the smart contract. Therefore, the power to interfere with the execution of the smart contract should be foreseen ex ante and be granted to a trusted third party. The latter is allowed to make determinations beyond the smart contracts' capabilities. It will feed the smart contract with information and, if necessary, influence its execution in order to reflect the trusted third parties' determination. $^{82}$

Independence from the traditional judiciary is granted by 'routine escrow mechanisms'. Rather than paying the sale price directly to the seller, the latter is kept in escrow by a third party. If no disputes arise from the contract, the funds held in escrow will be unblocked in favour of the seller. ${ }^{83}$ Nowadays, platforms adopt sophisticated systems based on 'multi-signature addresses', which do not really give exclusive control of the price to the third party involved as an adjudicator. ${ }^{8}$ This

$7^{8}$ Falco Kreis and Markus Kaulartz, 'Smart Contracts and Dispute Resolution - A Chance to Raise Efficiency?' (2019) 37 ASA Bulletin 336, 339 (affirming: 'If the parties revert to traditional means to resolve their dispute, the efficiency gained during the period of the contract performance will likely be significantly impaired').

79 Markus Kaulartz, 'Smart Contract Dispute Resolution' in Fries and Paal (n 26) 73, 74-75.

8० See, e.g., the 'Aragon Project' implemented on Ethereum is defined on the official website as 'a dispute resolution protocol formed by jurors to handle subjective disputes that cannot be resolved by smart contracts' (https://aragon.org/blog/aragon-court-is-live-on-mainnet). For other examples, cf. Amy Schmitz and Colin Rule, 'Online Dispute Resolution for Smart Contracts' (2019) J Disp Resol $103,116-122$.

81 See Section 16.3 .

$82 \quad$ Kreis and Kaulartz ( $\mathrm{n} 77$ ) 341.

83 See Ortolani (n 76) 433; Schmitz and Rule (n 80) 123.

84 The system is described by Ortolani, ibid., 434, as follows: 'This device essentially works like a lock with two keyholes; it can only be opened if two keys are used. Two parties entering into a transaction can use this device to store coins (for example, the price for the sale of certain goods), until the obligations arising out of that transaction have been performed. Both parties are provided with a digital key to the address; if no dispute arises, they can use the two keys to unlock the coins, jointly determining their final destination (typically, the address of the seller). In case of a dispute, however, neither party can access the coins autonomously, but either of them can ask a private adjudicator to 
should amount to an additional guarantee in favour of the contracting parties. ${ }^{85}$ The outcome is a kind of advanced ODR system, ${ }^{86}$ which is particularly suitable in the high-volume, low-value consumer complaints market. ${ }^{87}$

The autonomous dispute resolution system is not considered a modern form of the judiciary. ${ }^{88}$ It is presented as a return to the ancient pre-Westphalian past, where jurisdiction did not usually emanate from state sovereignty but from a private service, largely based on the consent of the disputing parties. Nevertheless, given the development of the modern state judiciary, there are many problematic aspects related to dispute resolution on blockchain platforms. For instance, it has been pointed out that: the decision is granted by subjects who do not necessarily have a juridical knowledge (often selected through a special ranking based on the appreciation of users), the decision cannot be recognized by a state court as happens with an arbitral award, and that enforcement does not respect time limits and safeguards provided by regular enforcement proceedings. ${ }^{89}$

With respect to the aforementioned issues, the fear is that such advanced ODR systems based on rules which are autonomous from the ones of national legal systems may limit the importance of the latter in regulating private relationships. ${ }^{9}$ On the other hand, some authors affirm that such procedures, under certain conditions, may become a new worldwide model of arbitration..$^{91}$

Also, in this case, the advantages of the dispute resolution procedures are strictly connected to the self-enforcement character of the decision. The legitimacy of such proceedings must be carefully assessed; the outcome should not necessarily be considered unlawful. The parties voluntarily chose to be subject to the scrutiny of the adjudicator, and from a private law perspective, the situation does not differ significantly from the case of a third arbitrator that determines the contents of the contract. In addition, the scope of automated enforcement does not tackle the entire estate; the assets that are subject to the assignment decided by the adjudicator are made available by the parties on purpose. It is not yet clear how far such proceedings will spread or whether they could functionally substitute for state court proceedings.

review the facts of the case and determine which of the two disputants is entitled to the disputed funds.'

85 See also the proposals of Wulf A. Kaal and Craig Calcaterra, 'Crypto Transaction Dispute Resolution' (2017-2018) 73 Bus Law 109 .

86 Schmitz and Rule (n 80) 114-124 (envisaging an 'ODR clause' to be implemented in the smart contracts).

87 See generally Richard Susskind, Online Courts and the Future of Justice (Oxford University Press 2019) 260-262.

88 Ortolani (n 76$) 434$.

89 Ortolani (n 76 ) $435-438$.

90 See Christoph Althammer, 'Alternative Streitbeilegung im Internet', in Florian Faust and HansBernd Schäfer (eds.), Zivilrechtliche und rechtsökonomische Probleme des Internet und der künstlichen Intelligenz (Mohr Siebeck 2019) 249, at 266-269.

${ }^{11} \quad$ See Gauthier Vannieuwenhuyse, 'Arbitration and New Technologies: Mutual Benefits' (2018) 35 I Int'l Arb 119 . 
Needless to say, in the absence of a specific recognition made by legal rules, these dispute resolution mechanisms are subject to the scrutiny of state courts. ${ }^{92}$ Although it could be difficult in practice, the party who does not agree with a decision, which is not legally recognizable, may sue the competent state court in order to have the dispute solved.

\subsection{CONCLUSION}

The actual dangers caused by the creation of private powers on blockchain platforms are related to the technology that grants automation of the contractual relationship. On the one side, if rights and legal guarantees are excluded or limited the adoption of self-enforcement devices should of course be considered unlawful. On the other side, however, in principle every situation has to be carefully assessed, as the contracting parties have freely chosen to enter into a smart contract.

Problems may exist when smart contracts are used as a means of self-help imposed by one of the contracting parties. An automated application of remedies may harm the essential interests of the debtors. Nevertheless, automation does not seem to infringe debtor's rights if enforcement is compliant with deadlines and legal steps provided by the law. Moreover, some economic advantages arising from automation may produce positive effects for whole categories of users and self-enforcement could also become an efficient tool in the hands of the European legislator, in order to significantly augment the effectiveness of consumer protection.

In the light of the issues examined herein, if the technology wishes to augment user trust about the functioning of smart contracts and blockchain, it should not aim to abandon the law. ${ }^{93}$ To be successful in the long run, innovative enforcement and dispute resolution models should respect and emulate legal guarantees. Smart contracts are not necessarily constructed with democratic oversight and governance, which are essential for a legitimate system of private law. ${ }^{94} \mathrm{~A}$ widespread acceptance of new services requires that the main pillars on which legal systems are based should not be erased.

92 Möslein (n 45).

93 See Kevin Werbach, 'Trust, but Verify: Why the Blockchain Needs the Law' (2018) 33 Berkeley Tech LI 487

94 See Mark Verstraete, 'The Stakes of Smart Contracts' (2019) 50 Loy U Chi LJ 743. 